\title{
Rapid prototyping and health: an ergonomic footrest to improve the venous return
}

\author{
Juliana Fernandes Pereira ${ }^{a}$ (D) João Eduardo Guarnetti dos Santos ${ }^{b}$ (D), Matheus Bertanha ${ }^{c}$ \\ a Faculdade de Arquitetura, Artes e Comunicação, Universidade Estadual Paulista Júlio de Mesquita Filho - FAAC, Bauru, SP, Brasil \\ b Departamento de Engenharia Mecânica, Universidade Estadual Paulista Júlio de Mesquita Filho - FEB, Bauru, SP, Brasil \\ ' Faculdade de Medicina, Universidade Estadual Paulista Júlio de Mesquita Filho - FMB, Botucatu, SP, Brasil \\ e-mails: julianafp08@yahoo.com.br; joao.guarnetti@unesp.br; matheusbertanha@gmail.com
}

\begin{abstract}
The worker who remains in a seated posture for a long time can develop different pathologies, like problems arising from the bad circulation of lower limbs. From this problem, a prototype of active footrest was developed, by rapid prototyping, to help the workers as well as the venous return of the lower limbs. After the prototype construction, was evaluated its effectiveness. First of all, the participants in this research were submitted to a previous test in the Botucatu's Clinical Hospital to check the venous health of lower limbs, and then, the prototype was tested for an evaluation through the water plethysmography apparatus, to verify possible modifications as the user's volumetry of lower limbs. The effective improvement as result was obtained concerning the venous return of lower limbs that used the prototype, about those which did not use it.
\end{abstract}

Keywords: footrest, design, 3D printing, vascular.

\section{Introduction}

The ergonomic design plays in a workstation, an essential role in the development and improvement of work efficiency and consequently, the workers' health, taking place through postural changes to perform the body movements corresponding to the necessary tasks, in order to promote and ensure the health, as well, their safety (Iida, 2016). According to the author, an ergonomic workstation has the duty to facilitate tasks, to capture and process data, and also helps to perform favorable body movements.

Some individuals, in certain services, remain in a sitting posture for a long period with their lower limbs in static permanence, generating a state that must be avoided, due to the fact that the posture prolongs the muscular contraction (Grandjean, 1998). After this muscle contraction, its capillaries are strangled due to increased internal pressure, causing fatigue to the muscle not properly irrigated. However, with the alternating movement of the calf muscle, as contraction and relaxation, the blood volume becomes up to 20 times greater in relation to rest, improving venous return (Iida, 2016).

Based on this previous knowledge, research was carried out that aimed to promote the improvement of venous return in working individuals who remain in a sitting posture for a long period. From this premise, a prototype was developed that allows the active movement of the lower limbs to promote the contraction and relaxation of the calf muscle and the increase in blood volume. The prototype was built using the software "Solidworks 2017" and printed through a FDM printer for usability tests, to prove its effectiveness in improving venous return. The participants' evaluation was carried out in stages. The first, being by the professor and doctor of the vascular laboratory at the Botucatu Medical School of UNESP at Botucatu city in the state of São Paulo, and then, the prototype test and volumetry evaluation, with the same participants, in a company in Bauru city located in the state of São Paulo, Brazil.

\section{Ergonomics and biomechanics for the work environment}

Ergonomics is the discipline that comprehends and studies the relations between a product and its user through studies, methods, and tests to stimulate the worker's quality of life and well-being in the system in which it operates (International Ergonomics Association, 2000). The study of organizational ergonomics, in other words, focusing on workplaces, should minimize the impositions related to the physical and cognitive areas of the worker. Organizational environments must promote to workers not only their productive performance improvement but also to prevent their health including maintenance. The branch 
of physical ergonomics also worked in environments is related to human anatomical characteristics, in addition to anthropometric, biomechanical, and physiological studies, thus, it is understood that it has great relevance in studies for the quality of life and well-being of the worker (Dul \& Weerdmeester, 2004).

The study of biomechanics, according to Helander (2006), a branch of ergonomics, can also be linked to the organizational issues of work, as it is essential to include its studies with design project methodology in addition to usability tests in design ergonomic, environmental and organizational at a workstation or bench, to avoid pathologies and musculoskeletal disorders resulting from poor posture.

To promote improvements to the workers' health who remain in a sitting posture for a long period, it is necessary some changes through projects that allow the movement of their lower limbs. The person who remains contracting a muscle, according to Vilela Junior et al. (2011), activates one or a set of muscles against a fixed resistance that implies muscle contraction. During this act, the blood capillaries can be strangled, with little blood supply in muscles, causing fatigue. The act to contract and relax the muscle, especially in the lower limb, the muscle of the calf acts as a blood pump activating the circulation of capillaries and increasing blood volume by up to twenty times in relation to rest (Iida, 2016). The muscle of the calf, according to Hoyle-Vaughan (2006), is considered the most important blood pump in terms of venous return, as it is responsible for draining blood against gravity and reduces intravenous pressure on the back of the foot during the resting state.

According to Campos et al. (2008), the active movement in relation to the passive movement and the rest, allows better consequences for health about the venous return. Thus, to provide an efficient venous return by increasing the blood volume of the lower limbs muscles, it is necessary to perform active movements or to do other work activities that allow the lower limbs movement during the workday. Based on this need, a project was created whose main objective was to allow the active movement of the individual while remaining in the same sitting posture during the working day.

\section{A footrest with active movement: the construction}

According to Iida (2016), there are several pathologies that can be triggered by sedentary activities or improper positions, mainly when the individuals remain in the same posture for a long time. Instruments such as footrests, help to reduce discomfort regarding staying in the same position. A stimulus, through instruments, to promote postural change or movement to the lower limbs, can assist in the calf muscle activation for better blood pumping and its venous return. Thus, from this problem, a study in design and ergonomics was carried out in order to create a prototype that would allow its user to perform movements while remaining in a sitting posture, to activate the calf muscle and avoid pathologies related to the vascular area.

The prototype was developed through ideas conceived by previous research carried out with thirty-five individuals who work in a sitting posture in a certain company in Bauru city. All employees of the chosen company participated in the research, being twenty-six women and nine men, aged between eighteen and sixty-two years old. It's important to note that all of them use footrests in their workstations, daily, footrests that allow light active movement (such as ankle flexion and amplitude), and the average time of use among all subjects is three years. The thirty-five participants (workers who maintained the sitting posture) evaluated four commercial footrests for a questionnaire, through the answers regarding usability. Three types of footrests were chosen due to their repeatedly acquired and due to easy access to the Brazilian market. And the fourth footrest was chosen by its functionality, due to the fact that this one has electronics components that allow passive movement to the lower limbs. According to the Figure 1, the first footrest allows a slight movement of the ankles (flexion and talocrural extension movements). The second one also provides the same active movement of the ankles as in the first. The third one does not allow any movement, only the rest of the lower limbs on an inclined surface at thirty degrees. And the fourth was an electronic footrest that allows the lower limbs passive movement.
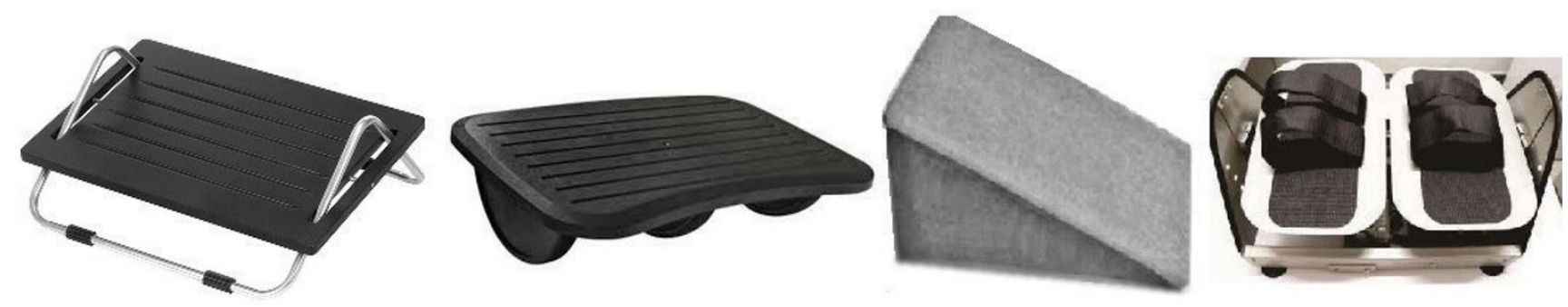

Figure 1. Four common footrests. 
Participants were asked about the degrees of perception in terms of usability, as comfort, ergonomics aspects, functionality, and pleasantness, through a non-visual evaluative linear scale encompassing a score from 0 to 10 . The time used in this evaluation was determined by each participant, in a purpose that they could obtain greater precision and certainty in their evaluations. The grade 0 would be assigned to the least favorable conditions, and grade 10 to the most favorable. About the initial result concerning the comfort item was obtained as a result for the first plantar support an average of 7.62 ; the second footrest an average of 6.78 ; the third one 5.17 and the fourth one 7.34. Descriptive justifications were also requested to indicate the reason for choosing the grade for each participant, based on the report of personal experiences with footrests, to include possibilities for recording complaints and suggestions for possible improvements in all four areas mentioned above. Thus, the first footrest obtained a better evaluation index because it allows the user to perform quick plantar flexion exercises, as it contains massaging textures in its base, contact with the sole, and the fact it has a $30^{\circ}$ inclination at rest. The second footrest does not guarantee the user the possibility of resting in static movement, since the rounded support structure between the floor and the base makes the object keep in constant movement, in addition to the base not having comfortable textures, making the foot slips off the surface. The third one, however, was not so well evaluated in comparison to the others, as it does not allow movements, does not have texture, and does not have adjustable angles. The fourth footrest obtained good feedback, as it allows the user to move without effort due to electronic elements.

As for pleasantness, the questioning was based on the visual aspect. The answers obtained were: first footrest with the average of 8.17 and justified by the harmonious composition of the elements and colors; the second footrest with an average of 6.84 , because its components are considered simple and unattractive, the third one with an average of 5.34 for the shape simplicity and type of material and the fourth footrest with an average of 5.84 for the fact that the object has a large dimension and is not dismountable.

Regarding functionality, the first footrest obtained an average of 8.06 for providing short movements and, at the same time allowing the feet to rest at the desired moment. The second one obtained a score of 7.06 for the possibility of performing movements, but it does not allow rest easily. The third one obtained an average of 5.12 for not allowing movement and the fourth footrest, 7.5 for performing passive movements. However, this same footrest does not allow rest at $30^{\circ}$.

The last question was regarding the ergonomic aspects. It was obtained that the first footrest reached the average
8.12 due to the relatively adequate height, and for having an inclined base according to the degree required by NR 17 according to Brasil (2012). The second got the average 7.06 because it has a sloping base but does not allow rest in acclivity, and the feet slip. The third footrest obtained 5.42 as an average, and its justification is because it does not have regulation or ways to move lower limbs. And the fourth footrest obtained an average of 8.45 for being of adequate height and for helping joints with greater frequency.

From their answers, focused on the acquisition of parameters for the prototype design development, it was possible to build a footrest that could integrate the characteristics required by the participants. Characteristics such as: a textured sole to massage and not allow the feet to slip on the base; an adequate inclination according to ergonomic regulations; to enable active movements as well as providing rest for the lower limbs; an adjustable height and harmonious elements, and colors; as well as provide the real active movement to lower limbs allowing movements not only at the ankles but for all the rest of the lower limbs, to provide improvements regarding the venous return. All of these requirements were met in the development of the prototype.

The questionnaire was carried out in order to understand the relationship between user and object, to provide the prototype with the reported positive characteristics. It's important to understand the user's satisfaction because the product satisfaction in a particular view of only one user can be considered a subjective view, however, in the view of several users, it becomes an objective data for the system and the creation of new objects (Wilson, 2010).

After this first stage, the data on the angle of the talocrural joint were also collected to be compared with the results obtained by anthropometric research conducted in Brazil by the National Institute of Technology (INT) in Manual Ergokit (Instituto Nacional de Tecnologia, 2008), in addition to the weight of the lower limbs on the footrest surface and the measures (length and width) of the feet given in centimeters. As the answer, it was obtained that the angulation measures acquired by the data collection were compatible with the measures available in the INT (Instituto Nacional de Tecnologia, 2008), allowing an inclination of the talocrural joint between 10 to 25 degrees to obtain comfort and efficiency in the proposed movement, with the angle of 10 degrees joint for flexion and 15 degrees for the extension. The weight of lower limbs on the surface of the footrest varied between $8 \mathrm{~kg}$ to $22 \mathrm{~kg}$, demonstrating the need to produce a footrest with a resistant material. The measurements of bare feet were also variable, with the length between $23.4 \mathrm{~cm}$ to $29.0 \mathrm{~cm}$, and width between $8.5 \mathrm{~cm}$ to $12.5 \mathrm{~cm}$. Thus, the prototype's pedal was printed according to the maximum foot measurements, admitting 
a small margin ( 1 centimeter) in the impression in order to consider the use with shoes.

Through the SolidWorks 2017 software, the prototype was created and, due to the facility in the physical design of the prototype, 3D printing was chosen as the means for production. It is known that $3 \mathrm{D}$ printing is a new area of manufacturing engineering whose main characteristic is construction through a predefined virtual model (Anderson, 2012). The rapid prototyping, as a term, expresses a complex of technologies for building solid parts, based on a threedimensional virtual object (Oliveira et al., 2009). This type of construction is expanding the concept of production, pointed out as a precursor of the new Industrial Revolution, due to the fact to allow the construction of prototypes, and being possible to build and transform products quickly and efficiently, facilitating and assisting in scientific research and even in the health area (Lipson \& Kurman, 2013).

Rapid prototyping done by the material addition process (Figure 2), as the current chosen method, has become the most used due to the $3 \mathrm{D}$ manufacturing techniques nowadays, since it is considered a faster and more economical process (reducing the waste of material, decreasing the energy costs and decreasing process time (Alcalde \& Wiltgen, 2018). Thus, the rapid prototyping by material addition process technique was the most viable option for the realization of the prototype, due to its agility and efficiency.

The simplicity in the objects' construction by rapid prototyping and its efficiency happens due to the following construction processes, according to Oliveira et al. (2009):

1) Virtual modeling object using $3 \mathrm{D}$ software. The modeling occurs by creating a three-dimensional drawing created by CAD software, transforming it into a virtual solid. From this, the solid is read by coordinates recognized by the software through algorithms, dividing it into layers, layers that can have different thicknesses stipulated by the 3D printer (Alcalde \& Wiltgen, 2018);
2) To the creation, the piece has to be standardized in STL format (surfaces in triangular meshes);

3) Investigation of archive data;

4) Part layers printing;

5) Post-process: removal of spare support material or support from the part.

It is important to note that 3D solid print quality may be susceptible to variations such as layer thickness, the table, surface, temperature at which it is subjected, specific changes to each equipment, orientation, as well as the pre and post-print process phases with the removal of excess material (Oliveira et al., 2009).

Among the current technologies, there are available printings as Stereolithography or SLA, Synthesizing or SLS, the laser, and the deposition merger or FDM. FDM is a technology used to print the prototype considered a lowcost production technology, currently its non-professional models have tables or desktops and are widely acquired (Alcalde \& Wiltgen, 2018). According to the authors, the FDM process uses thermoplastic filaments that are melted and ejected by the material extrusion nozzle. This extruder nozzle, as well as the table, can move according to the vertical axes (Z-axis), and horizontal axes ( $\mathrm{X}$ and $\mathrm{Y}$ axes), providing the material with the deposit through layers on layers.

The materials used in the present research for the construction of the prototype (Figure 3), were based on the materials of FDM technology, being:

- ABS (acrylonitrile, butadiene, and styrene) a thermopolymer formed by an elastomeric component and two amorphous thermoplastic components. It is a polymer widely used due to its aesthetics, as it allows decoration on its surfaces such as hot stamping and silkscreen, as well as accepting metallization and chrome-plating techniques (Landi \& Silva, 2003). According to Ultimaker (2017a), ABS has an excellent adhesion between the layers, making it
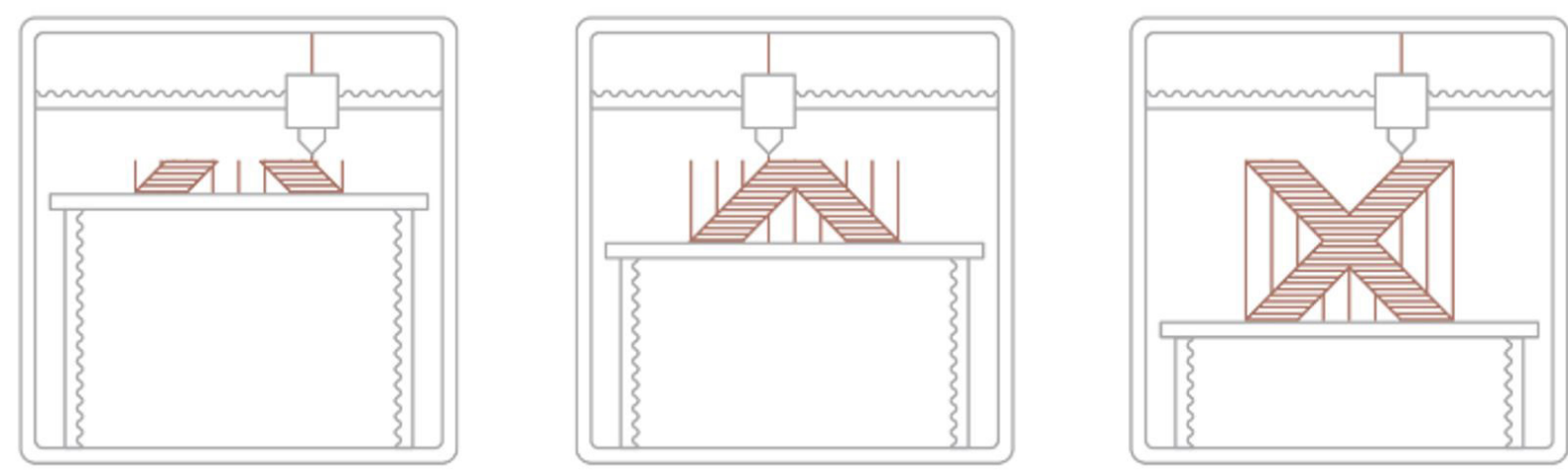

Figure 2. Material addition process by the 3D printer (Redwood et al., 2017). 


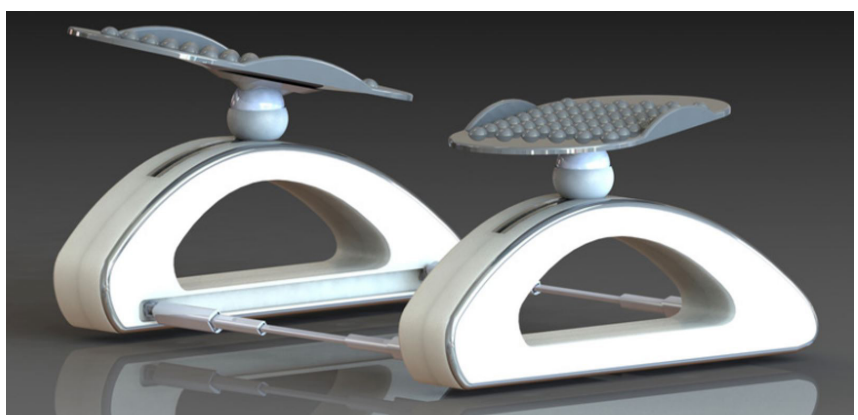

Figure 3. Footrest with active movement.

resistant, and provides minimal deformations, thus, it was used for the base of the footrest so that the surface could have a better finish;

- PLA, according to Melo et al. (2012) the poly (lactic acid) known as PLA is an aliphatic polyester made by chemical synthesis derived from lactic acid in the bacterial fermentation of glucose extracted from corn, in other words, a renewable source. It is a thermoplastic, biodegradable, with several applications and uses, in addition to having high fragility and rigidity (Kumar et al., 2010). And it is also resistant to traction and has good resolution, it was used for the production of the pedal (Ultimaker, 2017b);

- Nylon, a highly durable material, has resistance to abrasion and impacts, and is also resistant to many chemicals, facilitating its cleaning, so it was used for the texture of the pedal that can have direct contact with shoe soles (Ultimaker, 2017c).

Third parties were asked to produce the pieces using an FDM Mousta Builder Mega 3D printer with a volume of 300x200x320mm (WxDxH). The percentage of filling of the varied solid parts varies between 30 to $50 \%$, with 03 layers of the shell to ensure resistance due to the lower limbs weight between 8 to $22 \mathrm{~kg}$ and the pressure made on the material. As a flexible textured part on the base, a $40 \%$ filling configuration was used in addition to 04 layers of the shell to promote resistance. The production time varied according to the dimension of the piece. This configuration enabled the creation of a resistant prototype to the movement function and can be replicated to future footrest reprints, maintaining basic measurements and appropriate angles in new products with various formats.

During the footrest use, the user can define the speed at which the platforms or pedals move, according to the necessary comfort for movement, in order to simulate the walking movement, synchronizing the platform's movement for alternating or concomitance of plantar elevation and flexion, plantar inversion and eversion (talocrural joint angles).

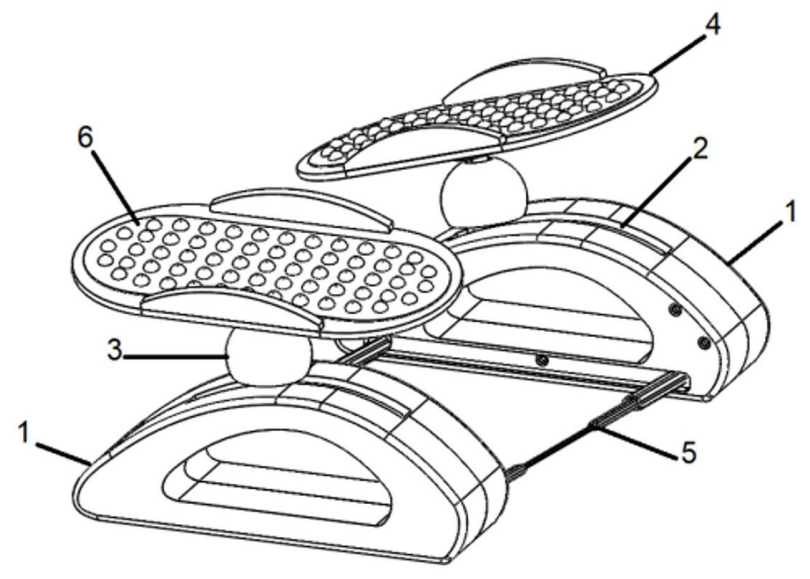

Figure 4. Prototype specifications.

For a better understanding, according to Figure 4, the prototype has two organic-shaped bases (1) with a rail (2) on each base, determining a path for a brief movement that follows the curvature of the base profile. The curvature has an appropriate angulation in accordance with NR 17- Brazilian Regulatory Norm No. 17 Ergonomics (Brasil, 2012) and INT (Instituto Nacional de Tecnologia, 2008) studies, which by a vertical axis, also allows circular movement. Above the rail has an axis in a vertical position that allows circular movement (3) with a flexible cover with texture (6), and attached to each axis, a platform for feet, where the individual performs movement (4). The bases are arranged adjacent and can be separated from each other, or connected using two telescopic rails with different designs (5).

\section{Results and discussions of the prototype evaluation}

The Brazilian Research Ethics Committee approved the present research, under the title "Active Footrest for the Work Environment: Assessment of Favorable Movements and Stimuli for Venous Return", with the registration number 2.185 .945 and CAAE number 70245317.9.0000.5663. All the research participants were properly instructed and signed the informed consent form.

To the evaluation, a randomized clinical trial was done with the same employees of the company that participated in the previous research with the four footrests evaluation, but applying at this stage to thirty workers, between 18 and 60 years old, who remain in a sitting posture during the workday. Five participants were excluded in relation to the total number of subjects from the previous evaluation, due to the requirements requested for the new stage. The exclusion criteria were used to exclude the five individuals who could be harmed in any way from the research, the criteria were: presentation of family history of thromboembolic disease, 
CEAP classification from $\mathrm{C} 3$, being in the puerperium, pregnancy, obesity, lower limbs wounds, diabetes, using anticoagulants, and using plaster or splints on the lower limbs.

The thirty individuals had their lower limbs classified into two groups: intervention and control group, generating a total of $n=60$. In this way, one of the lower limbs performed exercises while the other remained at rest.

Firstly, the participants were evaluated by USD (Ultrasound Doppler) at the Clinical Hospital of Medicine College - UNESP in Botucatu city, to evaluate individuals regarding the exclusion criteria. After this initial stage, during the working day at the company in Bauru, the participants' lower limbs were evaluated at 3 different times, on the water plethysmography apparatus, to evaluate the lower limbs' volumetry. The three moments of the evaluation were:

1) Just before the beginning of the exercise with the prototype: was recorded the initial water displacement of the two separated lower limbs. For the limb diameter standardization, the participants dipped the lower limbs, one at a time in the volumetric vat with water, and after measuring the volumetry, the area corresponding to the calf was measured by a tape measure, $10 \mathrm{~cm}$ below the tibial crest, and at the ankle (the diameter above the malleolus);

2) After the initial registration, the participant was submitted to the exercise with only one of his lower limbs (the member that belongs to the intervention group), leaving the other member at rest (belonging to the control group). And in the middle of the day, the measurement was performed again;

3) After the second measurement, the movement was performed again with the same lower limb and resting the other, in order to measure again at the end of the working day.

As a result of this stage, it was found that most of the participants in the control group (without the prototype using) had their lower limbs volume increased, indicating edema (swelling), compared to the initial state. The control group, with right and left lower limbs, obtained an average volume increase of $58.83 \mathrm{ml}$ in relation to the initial volume. And the intervention group that used the prototype in active movement, guaranteeing an improvement in venous return, obtained an average decrease in the lower limb volume of $152 \mathrm{ml}$ in relation to the initial volume. It was possible to obtain the final statistical data of the research regarding the lower limbs volume, through the BIOESTAT software indicating an effective improvement in venous return with the prototype use.

The results were submitted to the Kolmogorov-Smirnov normality test to verify whether the data were parametric, from this perspective, the average and standard deviation were obtained by the two independent samples by Test $T$. The Test $-T$ was used in this statistical study to determine the existence of significant differences between the data collected from two groups for their characteristics to be related. The two groups' data columns were the Intervention Group and the Control Group, analyzed in questions regarding volumetry and measurement of the lower limb areas.

With the results presented regarding the lower limbs volume (Table 1), the work with a significant $\mathrm{P}$ assumed at $0.05 \%$ was noticeable, generating statistical data at $\mathrm{P}=0.025$. The level of significance in the value of 0.05 , called $P$, was intended to indicate that the chance or risk of a difference when, in fact, there is no real difference, is $5 \%$. According to Campos et al. (2008), blood flow in active kinesiotherapy is more efficient than rest, and through the volumetry demonstration in this research, it was possible to verify that active movement through the prototype created by rapid prototyping, containing the appropriate configurations for material resistance in its function, and with anthropometric measurements according to ergonomic standards, was more effective than the maintenance at rest of the lower limbs of the participants who remain in the same sitting posture during the workday.

Thus, after the results regarding the use of the prototype and the significant decrease in the data on the volumetry of the lower limbs that perform the active exercise with the prototype, it was possible to understand the importance of a footrest that allows the increase of talocrural mobility and lower limbs' active movement as a walking simulation.

The differences between the prototype created and the footrests already existing on the market are: the prototype allows its user to perform an active movement that simulates walking, according to Campos et al. (2008), the performance of active movement in the lower limbs,

Table 1. The lower limbs volume.

\begin{tabular}{|c|c|c|}
\hline VOLUMETRY (LL) & AVERAGE (STANDARD DEVIATION) & $\begin{array}{c}\text { P Bilateral (Level of } \\
\text { significance in value of 0.05) }\end{array}$ \\
\hline CONTROL BEFORE & $1926.500 \mathrm{ml}(367.754)$ & \multirow{2}{*}{$\mathbf{0 . 9 8 1}$} \\
\hline INTERVENTION BEFORE & $192.666 \mathrm{ml}(362.876)$ & \multirow{2}{*}{$\mathbf{0 . 1 9 1}$} \\
\hline CONTROL MIDDLE & $1982.000 \mathrm{ml}(310.110)$ & \multirow{2}{*}{$\mathbf{0 . 0 2 5}$} \\
\hline INTERVENTION MIDDLE & $1879.833 \mathrm{ml}(288.876)$ & \\
\hline INTERTROL FINAL & $1920.166 \mathrm{ml}(323.919)$ & \\
\hline
\end{tabular}


concerning passive movement (electronic footrest) or static permanence can increase muscle tone, improve joint mobility such as talocrural and that combined with venous valve competence may improve venous return. Besides, the prototype's pedal is multi-axial and allows not only plantar flexion and extension, but also allows greater amplitudes of the talocrural joint, such as plantar eversion and inversion movements. Furthermore, it is possible to perform in the prototype the separate movement of each lower limb alternately, or with the lower limbs concomitantly.

\section{Conclusion}

Rapid prototyping has been adding and expanding the concept of construction and production due to the ease, agility, and quality of the projects' printing, assisting the researches in different areas.

Through previous evaluations, it was possible to identify the characteristics necessary for the construction of an ergonomic footrest prototype, to meet the basic requirements of the ergonomic regulatory standards and the characteristics suggested and evaluated by the footrest's users, referring to their experiences in their use.

The present research used rapid prototyping, by means of a FDM printer to produce its prototype, which one, through its evaluation, brought improvements to its users. About the results obtained with the prototype test, according to the sample from the final stage of data collection, $n=30$ from the control group, it was possible to identify how the physical process of the individuals' lower limbs who remain in a sitting posture occurs, regarding the venous return. The assessment was carried out during the day in order to faithfully reproduce the workers' routine for a day. The same subjects who participated with the lower limb in the control group, also participated with the other lower limb as an intervention group, totaling an $n=60$, (by the method of randomization in the choice of lower limbs), to reproduce the routine of workers in a sitting posture. As a final result, it was possible to observe the difference between the volumetry of the groups, bringing statistical data on the improvement in relation to edema. Through this research, it was possible to affirm the active movement by the prototype printed, in relation to the basal value, generated improvement in the blood flow due to the effectiveness of the muscular compression of the calf or sural pump, given by the contraction of the musculature, reducing the stasis in the segment.

From these positive results descendants from the good execution of the prototype, it is expected to create new prototypes with different designs, using the printing configuration already stipulated by this research, being suitable for the replication of this type of product.

\section{Acknowledgements}

Thank the Coordination for the Improvement of Higher Education Personnel (CAPES) for granting the master's scholarship.

\section{References}

Alcalde, E., \& Wiltgen, F. (2018). Estudo das tecnologias em prototipagem rápida: passado, presente e futuro. Revista Ciências Exatas, 24(2), 12-20.

Anderson, C. (2012). Makers: the new industrial revolution. São Paulo: Elsevier.

Brasil. Ministério do Trabalho. (2012). Manual de aplicação da norma regulamentadora $n^{\circ} 17$ (NR-17) (2. ed.). Brasília: MET.

Campos, C. C. C., Albuquerque, P. C., \& Braga, I. J. S. (2008). Avaliação do volume de fluxo venoso da bomba sural por ultra-sonografia Doppler durante cinesioterapia ativa e passiva: um estudo piloto. Jornal Vascular Brasileiro, 7(4), 325-332.

Dul, J., \& Weerdmeester, B. (2004). Practical ergonomics (2. ed.). São Paulo: Edgard Blucher.

Grandjean, E. (1998). Ergonomics manual: adapting work to man (4. ed.) Porto Alegre: Bookman.

Helander, M. (2006). A guide to human factors and ergonomics (2. ed.). New York: Taylor \& Francis Group.

Hoyle-Vaughan, G. (2006). Treatment of leg ulcers. Emergency Nurse. 14 (5), 24-27.

Iida, I. (2016). Ergonomia: projeto e produção (2. ed). São Paulo: Editora Blucher.

Instituto Nacional de Tecnologia - INT. (2008). Manual Ergokit. Rio de Janeiro: Divisão de Desenho Industrial, Instituto Nacional de Tecnologia. Retrieved in 2020, July 20, from http://www.int.gov.br/Novo/Desenho_Industrial/ergokit.html

Kumar, M., Mohanty, S., Nayak, S. K., \& Parvaiz, M. R. (2010). Effect of glycidyl methacrylate (GMA) on the thermal, mechanical and morphological property of biodegradable PLA/PBAT blend and its nanocomposite. Bioresource technology, 101(21), 8406-8415.

Landi, T. R. L., Silva, L. G. A. (2003). Study of the effect of ionizing radiation with electron beam on Acrylonitrile Butadiene Styrene-ABS terpolymer. Journal Mackenzie Engeneering and Computation, 4(4), 107-117.

Lipson, H., \& Kurman, M. (2013). Fabricated the new world of $3 D$ printing. Hoboken: John Wiley \& Sons.

Melo, T. J. A., Araújo, E. M., Agrawal, P., \& Brito, G. F. (2012). Tenacificação do poli(ácido lático) pela adição do terpolímero (etileno/acrilato de metila/metacrilato de glicidila). Polímeros: Ciência e Tecnologia, 22(2), 164-169.

Oliveira, M. F., Maia, I. A., Al-Chueyr, T., Paschoal, G. H. L., Bernardes, L. F., Moreira, L. C., \& Silva, J. V. L. (2009). 
Explorando os recursos das tecnologias de prototipagem rápida - SLS e FDM - em aplicações especiais. In Anais do $10^{\circ}$ Congresso Brasileiro de Polímeros. São Paulo: IPEN.

Redwood, B., Schöffer, F., \& Garret, B. (2017). The 3D printing handbook - technologies, design and applications. Amsterdã: Coers\&Roest 3D Hubs B.V.

Ultimaker. (2017a). ABS datasheet. Utrecht: Ultimaker.
Ultimaker. (2017b). PLA datasheet. Utrecht: Ultimaker. Ultimaker. (2017c). Nylon datasheet. Utrecht: Ultimaker.

Vilela Junior, G. B., Hauser, M. W., \& Oliveira A. L. (2011). Kinesiology and biomechanics. Ponta Grossa: UEPG.

Wilson, C. (2010). User experience re-mastered - your guie to getting the right design. Burlington: Morgan Kaufmann. 